\section{Applied Composite Materials}

March 2008, Volume 15, Number 2 : Pages 87-97

http://dx.doi.org/10.1007/s10443-008-9059-1

(c) 2008 Springer. Part of Springer Science+Business

Media

The original publication is available at http://www.springerlink.com
Archimer, archive institutionnelle de l'Ifremer http://www.ifremer.fr/docelec/

\title{
Marine Composites Based on Low Styrene Content Resins. Influence of Lamination Procedure and Peel Plies on Interlaminar Resistance
}

\author{
Yves Perrot $^{1}$, Peter Davies ${ }^{2, *}$, André Kerboul $^{2}$ and Christophe Baley ${ }^{3}$
}

\author{
${ }^{1}$ Société Nautique Conseil Développement, Technopole Brest Iroise, 29200 Brest, France \\ ${ }^{2}$ Materials \& Structures group, IFREMER Brest Centre, 29280 Plouzané, France \\ ${ }^{3}$ Laboratoire L2PIC, Université de Bretagne Sud, 56321, Lorient, Cedex, France \\ *: Corresponding author : P. Davies, email address : Peter.Davies@ifremer.fr
}

\begin{abstract}
:
Delays between lamination of structures and secondary bonding are common in boatbuilding. This paper presents results from an experimental study of the influence of manufacturing procedure on the bond strength of unidirectional glass fibre reinforced polyester composites. Continuously laminated panels are taken as the reference and compared with panels overlaminated after delays of one week with and without peel ply protection. A standard polyester and low styrene DCPD formulation were tested. ILSS testing is shown not to be sensitive to the procedure but crack propagation tests show very large differences in mode I fracture energy. A small drop in fracture energy is measured for a delay of one week between lamination of the first and second halves of the specimen without peel ply. When a nylon peel ply is applied and removed just before overlamination of the second half very large drops in propagation energy, around $75 \%$, are noted for both materials. Surface abrasion after peel ply removal enables fracture energy to be recovered for the standard polyester and to a lesser extent for the low styrene DCPD composite.
\end{abstract}

Keywords: Glass/polyester composites - Low styrene content resins - Lamination procedure - Peel ply - ILSS - Mode I 


\section{Introduction}

During boat manufacture GRP (glass reinforced plastic) mouldings are produced in steps, by first laminating secondary structures such as stiffeners or bulkheads to the hull or deck mouldings and then assembling these. This involves bonding onto a partially cured structure, and guaranteeing the integrity of these assemblies is critical to the safety and long term durability of the structure. Such assemblies are not limited to the marine industry but in nautical construction the materials are rarely post-cured. The polyester resins employed in the majority of these applications will continue to cure after manufacture but residual styrene can also evaporate from the surface, leading to variations in stoichiometry. The longer the delay between manufacture and assembly the more difficult it is to create strong bonds with the surface. In a previous study on overlamination of composites based on traditional polyester resins it was shown that tests to measure crack propagation resistance were more sensitive to the state of the surface than the simple short beam shear and flexural tests frequently used for quality control [1]. However, in recent years under pressure from environmental legislation to reduce volatiles in boatyards, these resins are being replaced by low styrene formulations [2]. Low styrene emission resins contain film-forming additives at the surface, such as paraffin waxes, and these have been shown to affect secondary bond strength [3]. However, an alternative formulation developed in the USA and available in Europe for the last 10 years is based on DCPD (dicyclopentadiene) chemistry. This allows lower styrene content by changing the cure chemistry, the DCPD partly replaces the glycol component.

In order to protect surfaces to be bonded in the workshop peel plies are frequently employed. These are fine weave cloths of nylon or polyester fibres which are impregnated with resin as a final layer and peeled off just before bonding. There is a wide range of peel plies on the market and to enable easy removal many are coated with products such as silicones of fluorocarbons. Several studies for the aeronautical industry using carbon/epoxy composites have highlighted the risks of contamination by traces of these products if no additional surface preparation is applied [4-6]. Recent results from tests on glass/epoxy composites indicated improved lap shear strength with polyamide peel plies compared to polyester, and showed the importance of surface morphology after peel ply removal $[7,8]$. Kieronski et al also examined the use of peel plies to protect glass reinforced epoxy composite surfaces [9]. They showed that while an optimal peel ply can leave a surface ready for secondary bonding without further treatment, if a "sub-optimal" peel ply is used its removal can leave a thin skin of polymer on the surface, which inhibits subsequent bonding. They found that nylon peel plies, which were more difficult to remove than polyester, left more residues than the polyester. Bond failures were then adhesive rather than cohesive.

Very little work has addressed this issue for applications other than aeronautical, even though secondary bonding is applied to thousands of GRP boat structures every year, both during manufacture and in repair operations.

In the present study the influence of three parameters on the quality of secondary bonding of marine composites is examined :

the delay between initial and secondary lamination

the surface preparation, and

the type of polyester resin.

The aim is to compare the behaviour of low styrene emission DCPD based polyester with that of a traditional polyester resin.

\section{Material and lamination procedure}

Two laminating resins have been studied : a standard orthophthalic polyester (A) and a low styrene content DCPD (dicyclopentadiene) polyester (B). Their styrene contents and mechanical properties, measured in a previous study [10], are shown in Table 1.

In order to manufacture composite panels these resins were mixed with $1.5 \%$ by weight of an MEKP (methyl ethyl ketone peroxide) catalyser and reinforced with 24 unidirectional layers of $300 \mathrm{~g} / \mathrm{m}^{2} \mathrm{E}$ glass reinforcement (Sicomin SA). Contact moulding was used with roller impregnation, resulting in a fibre volume content of between 35 and $38 \%$ by volume.

For each resin four different manufacturing procedures were examined, (Table 2) :

1 - continuous lamination ;

2 - lamination of half the composite thickness, 12 layers, a pause of one week in the workshop, followed by lamination of the second half with no further surface preparation ; 
3 - lamination of half the composite thickness with a silicone-free polyamide 66 peel ply, a pause of one week in the workshop, removal of the peel ply and lamination of the second half;

4 - lamination of half the composite thickness with a polyamide 66 peel ply, a pause of one week in the workshop, removal of the peel ply, grinding of the surface and lamination of the second half.

It should be noted that according to the suppliers this peel ply is intended to provide a surface which is ready for bonding without further mechanical abrasion. Figure 1 shows the peel ply fabric surface before application.

Each panel was then cured for 24 hours at room temperature and 16 hours at $40^{\circ} \mathrm{C}$. This cure cycle has been shown to result in a cure state close to that measured on industrial structures [11]. The panel thicknesses are shown in Table 2 . In order to perform interlaminar fracture tests an $80 \mathrm{~mm}$ long starter film (8 micron thick polypropylene) was placed at mid-thickness of each panel.

\section{Tests performed}

Two types of interlaminar test have been performed. First, the short beam shear test was used, based on the ISO test method [12] applied to samples without implanted defects. Specimen dimensions were $25 \mathrm{~mm}$ width and $50 \mathrm{~mm}$ long. A ratio of distance between supports to thickness of 5 and a loading rate of $4 \mathrm{~mm} / \mathrm{min}$ were used. Mode I interlaminar fracture tests were then performed, on double cantilever beam (DCB) specimens to measure crack initiation and propagation from starter films (Figure 2). Aluminium blocks were bonded to the specimen ends to allow load introduction. The ISO 15024 document describes the test procedure [13]. The specimen geometry is $20 \mathrm{~mm}$ wide, 200 $\mathrm{mm}$ long, initial starter crack length $a_{0}=50 \mathrm{~mm}$ and loading rate $2 \mathrm{~mm} / \mathrm{min}$. Analysis of results was performed using Berry's method [14] with the following expression:

$$
G_{1}=\frac{n F \delta}{2 b a}(1)
$$

with, $F$ the load, $\delta$ the displacement and a the crack length measured during the test. $b$ is the specimen width and $n$ an experimental parameter corresponding to the slope of the plot of compliance $(\delta / F)$ versus crack length.

For each test at least four specimens were tested per material. An Instron 4302 testing machine was used with a $10 \mathrm{kN}$ load cell for ILSS and a $500 \mathrm{~N}$ load cell for DCB tests. Critical strain energy release rates were measured at initiation (non-linearity on the load-displacement plot), $\left(G_{1 c}\right)$, and throughout propagation $\left(G_{1 p}\right)$. The values of the latter presented here are mean values over the crack lengths between 100 and $140 \mathrm{~mm}$.

In order to check the cure state after manufacture differential scanning calorimetry was used with a modulated DSC (DSC 2920 - TA Instruments) over a temperature range from $-20^{\circ} \mathrm{C}$ to $180^{\circ} \mathrm{C}$ at a heating rate of $5^{\circ} \mathrm{C} / \mathrm{min}$. Samples with a weight of $10 \mathrm{mg}$, were taken from the the surfaces of DCB specimens. A glass transition temperature was measured as the inflexion point on the reversible enthalpy plot. FTIR (Fourier Transform InfraRed) spectroscopy was performed on fracture surfaces using a Thermo Nicolet Nexus equipment. Samples were studied using ATR on a ZnSe crystal. Fracture surfaces of DCB specimens were examined with an optical microscope then in a Jeol JSM 6460LV Scanning Electron Microscope. Energy dispersive x-ray microanalysis (EDXA) was used to analyse surface elements.

\section{Results and Discussion}

Tests were performed three weeks after specimen fabrication. Table 3 presents the results from DSC analyses performed on samples taken from the fracture surfaces of specimens manufactured by route 3 just after testing, and show a similar cure state for the two resins.

ILSS

The short beam shear test involves tension and compression loads on the specimen surfaces but interlaminar shear through the sample thickness, with a maximum shear stress at the mid-thickness 
[15]. The materials tested here, with different manufacturing conditions resulting in variations at midthickness, should be sensitive to this type of loading. Figure 3 shows the results.

- Continuous lamination (1) : The ILSS values are similar and close to $40 \mathrm{MPa}$ for the two resins. These values are typical of unidirectional glass reinforced composites with around $35 \%$ fibre volume [16].

- Lamination after a delay of one week (2) : a small drop in ILSS is noted for the standard polyester (35 MPa), as might be expected if there is a loss of styrene and fewer free radicals available for reaction with the new resin. The results for the low styrene resin are contradictory, ILSS increases slightly.

- Lamination after one week but with a peel ply (3). Here ILSS increases slightly for both resins compared to the continuous lamination value. This might be attributed to mechanical interlocking effects caused by a rougher surface left after removal of the peel ply. The importance of surface roughness was shown by Besnard [8] for lap shear glass/epoxy samples.

- Same preparation as (3) but with surface abrasion after peel ply removal (4). The standard polyester shows an ILSS value similar to (2), suggesting that abrasion may reduce the surface roughness present after peel ply removal, while the DCPD resin shows an increase.

Overall the differences in ILSS are small, whatever the surface preparation. They would not be sufficient to cause alarm in a boatyard and the values would probably all be considered roughly equivalent.

Mode I

Figure 4 shows examples of load versus displacement plots from the mode I tests for the different manufacturing conditions. Propagation was stable in all cases. From these recordings resistance or Rcurves, showing strain energy release rate $G_{1}$ versus crack length $a$, can be constructed. Figures 5 and 6 show the results. Critical values of $G_{1}$ at initiation $\left(G_{1 c}\right)$ and propagation $\left(G_{1 p}\right)$ are presented in Table 4. Values at initiation are similar and are all in the range 60 to $140 \mathrm{~J} / \mathrm{m}^{2}$. There is more scatter for the standard polyester but the values do not seem to be affected by the laminating conditions. The values measured during crack propagation are strongly dependent on lamination conditions however.

The composites produced by continuous lamination show higher crack propagation resistance than those produced in two steps. A delay of one week before overlamination, procedure 2 , results in a drop in crack propagation resistance of around 10 to $30 \%$ compared to continuous lamination. These comments are true for both resins, and reflect the change in surface composition as residual styrene and free radicals are lost. The application of a peel ply which is removed just before bonding with no further surface treatment, procedure 3, results in a very significant drop in $G_{1 p}$ for both resins. Values are lower than those for an unprotected surface. Similar results were noted previously for a standard isophthalic polyester resin [1], and underline the care needed when using peel plies. When the surface is abraded after removing the peel ply, procedure 4, the resulting interface strength is improved and for the standard polyester values return to the level of those measured after a week's delay with no peel ply. For the low styrene polyester this is not the case, the surface abrasion increases fracture energy values slightly but they remain well below those for procedures 1 and 2 . In general the strain energy release rates are higher for the standard polyester composite bonds than for the low styrene DCPD formulation.

\section{Discussion}

The mode I results for continuous lamination and the delay of one week are as expected, a drop in toughness of up to $30 \%$ is measured when the lamination is interrupted, which can be attributed to the lower reactivity of the surface, which has started to cure when the material is left for a week. The result which is not expected is that involving the peel ply. Figure 7 shows the fracture surfaces corresponding to the specimens overlaminated after removing a peel ply (Procedure 3 ). These clearly indicate the imprint of the peel ply weave. There is very little evidence of any adhesion except for small areas on the standard polyester composite surface. Similar photos have been presented for other composites [1].

There are at least three mechanisms which might explain this result. First, the peel ply may contain a release agent which could contaminate the surface. Peel ply and fracture surfaces were examined using FTIR spectroscopy and EDAX. The former allowed the identification of the peel ply fabric as polyamide, but no other substances were detected. However the quantities necessary to impede 
adhesion may be very small, so these analyses do not allow this hypothesis to be conclusively excluded.

A second possibility is that proposed by Kieronski et al [9], that part of the peel ply fabric itself is left on the surface after peel ply removal. The properties of polyamide fibres are closely related to manufacturing conditions, but published studies have revealed the existence of a core/skin structure [17]. The outer few microns of the fibres were found to be more highly oriented than the centre, and subjected to compressive residual stresses. The hypothesis that the transverse loading of the fibre during peel ply removal may result in removal of this outer layer appears plausible. In order to examine this, SEM photos were taken of both a new surface just after peel ply removal, one week after lamination, Figure 8, and the surface of the corresponding removed peel ply, Figure 9. Figures $8 a-c$ show the new surface and there is no sign of any residual fibre even at very high magnification. The only marks visible are small axial lines corresponding to the die marks when the fibre is extruded, Figure 8c. Such lines are often seen on polyamide fibres [18]. Similar lines can also be seen at high magnification on the peel ply after removal, Figure 9c, and this suggests that no material has been removed from the peel ply. Only one small area of damage to fibres was noted, shown in Figure 9b, and this may be due to abrasion after removal. While fibre residues may be left in some cases this mechanism does not appear to be responsible for the poor bond strengths measured here.

A third possibility is that the presence of the peel ply affects the cure process. Skrifvars et al have discussed inhibition of cure in air (without peel ply) which might leave a more tacky surface which is more receptive to secondary bonding [3]. DSC analysis was performed on both a new surface revealed by the peel ply removal after one week and on the other side of the same sample, which was unprotected and cured in air. The results are shown in Table 5. Both surfaces have glass transition temperatures below that of the post-cured material and the values for the surface below the peel ply are slightly higher than those for the surface cured in air but the difference between the values is small.

At this time we have no satisfactory explanation for the poor adhesion to surfaces protected by this peel ply. Further work is in progress, but the results, showing that for low styrene polyester resin composites as well as for standard materials, peel plies cannot be relied on to provide an optimal surface for bonding even after grinding, are presented as the practical consequences are important.

\section{Conclusion}

The strength of the bond between a polyester composite substrate and an overlaminate depends on : The delay between manufacture of the first laminate and secondary bonding .

The use of a peel ply. Overlamination immediately after peel ply removal results in a very weak interface. Further surface treatment after peel ply removal may enable part of the strength to be recovered.

The nature of the polyester resin. The low styrene DCPD resin tested here showed lower resistance to crack propagation at secondary bonds than a standard polyester prepared under the same conditions. The difference is most striking when a surface protected by a peel ply is abraded : this allowed the standard polyester composite bond to recover most of its strength but the low styrene formulation remained very weak.

The mechanism proposed by Kieronski et al [9], nylon fibre residue left on the surface after peel ply removal, appears to be a plausible explanation for the poor adhesion, but no fibre residues were detected here.

This study also underlined the poor sensitivity of the ILSS test to bond-line defects. Quality control of critical interfaces requires alternative tests and mode I crack propagation testing appears well-suited to this task.

Finally, in addition to their widespread use for contact moulding, low styrene DCPD resins are increasingly being used in infusion moulding. It is important that adequate surface preparation procedures be developed for secondary bonding onto these mouldings if costly failures are to be avoided. Based on the results above it is strongly recommended that preliminary bonding tests be performed before any new application is envisaged. 


\section{Acknowledgements}

The contribution of Philippe Crassous of IFREMER to the SEM examinations is gratefully acknowledged.

\section{References}

[1] Davies P, Baley C, Loaec H, Grohens Y, Interlaminar tests for marine applications, Evaluation of the influence of peel plies and fabrication delays, App. Comp. Materials, 2005, 12, 293-307.

[2] Marsh G, Reduced styrene content offers answer for LSE, Reinforced Plastics, December 2001, 24-30

[3] Skrifvars M, Berglund L, Ericson M, Microscopy of the morphology in low styrene emission glass fiber/unsaturated polyester laminates, J. Appl. Polymer Sci., 71, 1999, 1555-1562.

[4] Davis M, Bond D, Principles and practices of adhesive bonded structural joints and repairs, Int. Jnl Adhesion \& Adhesives, 19, 1999, 91-105.

[5] Hart-Smith L. J. A peel-type durability test coupon to assess interfaces in bonded, co-bonded, and co-cured composite structures, Int J Adhesion and Adhesives, 19, 2-3, 1999, 181-191.

[6] Armstrong KB, Effect of adsorbed water in CFRP composites on adhesive bonding, Int. J. Adhesion \& Adhesives, 16, 1996, 91-105.

[7] Besnard Q, Fois M, Grisel M, Peel ply surface treatment for composite assemblies: chemistry and morphology effects, Composites Part A, 36, 2005, 1562-1568.

[8] Besnard Q, Fois M, Grisel, Influence of fibre reinforcement and peel ply surface treatment towards adhesion of composite surfaces, Int. J. Adhesion \& Adhesives, 25, 2005, 404-409.

[9] Kieronski EA, Knock KK, Fallon WP, Walker GM, Mechanism of adhesive bonding of fibreglass composites with peel ply surface preparation, ASTM STP 1455, 2004, 78-91.

[10] Perrot Y, Baley C, Grohens Y, Davies P, Damage Resistance of Composites Based on Glass Fibre Reinforced Low Styrene Emission Resins for Marine Applications, Applied Composite Materials, Vol 14, 1, 2007, 67-87

[11] Baley C, Perrot $Y$, Davies $P$, Bourmaud A, Grohens $Y$, Mechanical properties of composites based on low styrene emission polyester resins for marine applications, Applied Composite Materials, 2006, Vol. 13, 1, pp1-22.

[12] ISO 14130 : 1997, Fibre-reinforced plastic composites -- Determination of apparent interlaminar shear strength by short-beam method.

[13] ISO 15024 : 2001, Fibre-reinforced plastic composites - Determination of mode I interlaminar fracture toughness, $G_{I C}$, for unidirectionally reinforced materials.

[14] Berry JP, Determination of fracture surface energies by the cleavage technique, Jnl Applied Physics, 34, 1963, 62.

[15] J. M. Whitney, C. E. Browing, and A. Mair, Analysis of the flexure test for laminated composite materials, in: Proc. of 3rd Composite Materials Conference, ASTM STP546 (1974), p. 30.

[16] Baley C, Davies P, Grohens Y, Dolto G, Application of Interlaminar Tests to Marine Composites. A Literature Review, Applied Composite Materials Volume 11, Issue 2, Mar 2004 99-126

[17] Marcellan A, Bunsell AR, Piques R, Colomban P, Micro-mechanisms, mechanical behaviour and probabilistic fracture of PA66 fibres, J. Mat. Sci 38, 2003, 2117-2123.

[18] Hearle JWS, Lomas B, Cooke WD, Atlas of fibre fracture and damage to textiles, $2^{\text {nd }}$ edition, 1998, CRC/ Woodhead publishing 
Tables

\begin{tabular}{lllll}
\hline Resin & $\begin{array}{l}\text { Styrene } \\
\text { content } \\
(\% \mathrm{wt})\end{array}$ & $\begin{array}{l}\text { Young's modulus } \\
(\mathrm{GPa})\end{array}$ & $\begin{array}{l}\text { Failure stress } \\
(\mathrm{MPa})\end{array}$ & $\begin{array}{l}\text { Failure strain } \\
(\%)\end{array}$ \\
\hline A (standard) & 49 & $3.7 \pm 0.2$ & $49 \pm 10$ & $1.6 \pm 0.5$ \\
\hline B (low styrene DCPD) & 38 & $3.2 \pm 0.1$ & $38 \pm 3$ & $1.4 \pm 0.2$ \\
\hline
\end{tabular}

Table 1 - Initial properties of resins studied [11]

\begin{tabular}{|l|l|l|l|l|}
\hline & & & \multicolumn{2}{|l|}{$\begin{array}{l}\text { Composite thickness } \\
(\mathrm{mm})\end{array}$} \\
\hline $\begin{array}{l}\text { Lamination } \\
\text { reference }\end{array}$ & $\begin{array}{l}\text { Time between first substrate } \\
\text { fabrication and overlamination }\end{array}$ & Surface preparation & A & B \\
\hline 1 & 0 & Continuous & $7.4 \pm 0.1$ & $7.6 \pm 0.1$ \\
\hline 2 & 1 week & No peel ply & $7.9 \pm 0.1$ & $8.0 \pm 0.3$ \\
\hline 3 & 1 week & Peel ply & $7.5 \pm 0.3$ & $7.8 \pm 0.2$ \\
\hline 4 & 1 week & $\begin{array}{l}\text { Peel ply and } \\
\text { preparation }\end{array}$ & $7.4 \pm 0.3$ & $7.7 \pm 0.1$ \\
\hline
\end{tabular}

Table 2 - Lamination procedures and composite thicknesses.

\begin{tabular}{|l|l|l|}
\hline Composite & Lamination reference & $\operatorname{Tg}\left({ }^{\circ} \mathrm{C}\right)$ \\
\hline A & 3 & $67 \pm 2$ \\
\hline B & 3 & $70 \pm 2$ \\
\hline
\end{tabular}

Table 3 - Glass transition temperature after manufacture and post-cure.

\begin{tabular}{|l|l|l|l|l|}
\hline \multicolumn{2}{|l|}{ Composite A } & \multicolumn{2}{l|}{ Composite B } \\
\hline $\begin{array}{l}\text { Lamination } \\
\text { reference }\end{array}$ & $\mathrm{G}_{\mathrm{IC}}\left(\mathrm{J} / \mathrm{m}^{2}\right)$ & $\mathrm{G}_{\mathrm{Ip}}\left(\mathrm{J} / \mathrm{m}^{2}\right)$ & $\mathrm{G}_{\mathrm{Ic}}\left(\mathrm{J} / \mathrm{m}^{2}\right)$ & $\mathrm{G}_{\mathrm{Ip}}\left(\mathrm{J} / \mathrm{m}^{2}\right)$ \\
\hline 1 & $146 \pm 37$ & $630 \pm 70$ & $109 \pm 33$ & $529 \pm 22$ \\
\hline 2 & $59 \pm 19$ & $456 \pm 57$ & $104 \pm 6$ & $461 \pm 35$ \\
\hline 3 & $90 \pm 28$ & $168 \pm 41$ & $109 \pm 8$ & $93 \pm 19$ \\
\hline 4 & $81 \pm 18$ & $366 \pm 67$ & $98 \pm 21$ & $169 \pm 60$ \\
\hline
\end{tabular}


Table 4 - Initiation and propagation surface energies for different lamination procedures.

\begin{tabular}{|l|l|l|}
\hline Sample & Lamination reference & $\operatorname{Tg}\left({ }^{\circ} \mathrm{C}\right)$ \\
\hline Surface in air & 3 & $50 \pm 2$ \\
\hline Surface peel ply & 3 & $59 \pm 4$ \\
\hline
\end{tabular}

Table 5 - Glass transition temperatures one week after lamination, on surface revealed by peel ply removal and on surface exposed to air.

\section{Figures}

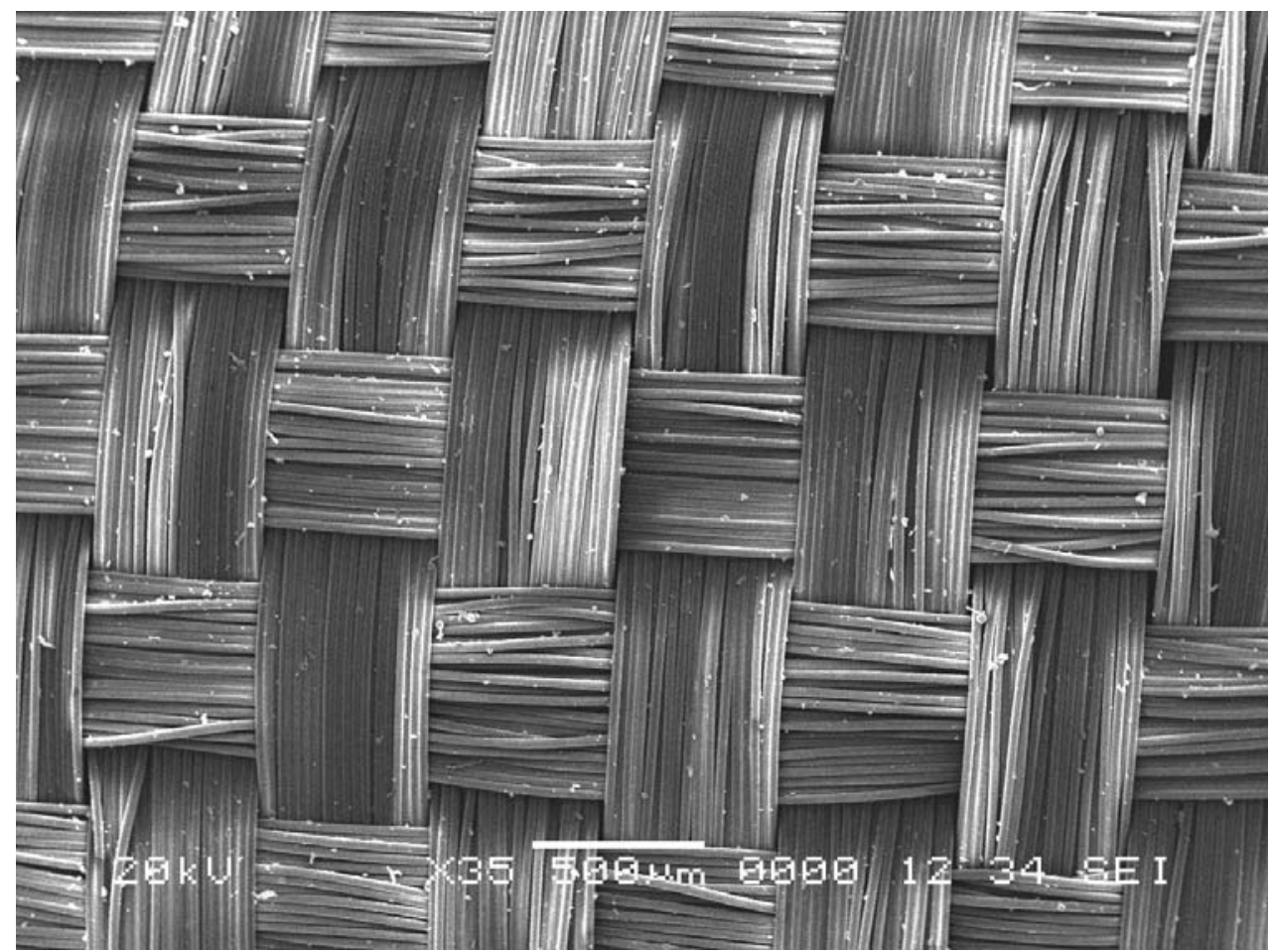

Figure 1. Polyamide peel ply fabric surface SEM photo.

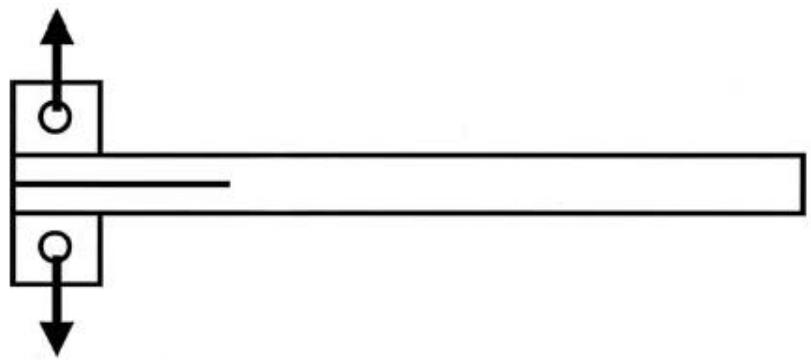

Figure 2. Mode I DCB specimen. 


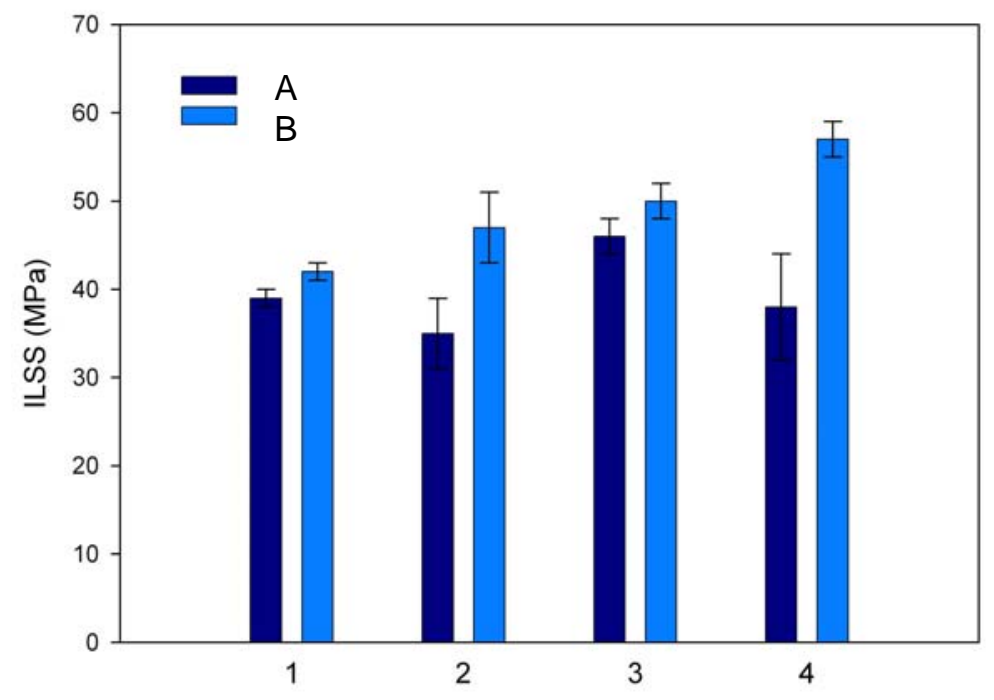

Figure 3. ILSS results

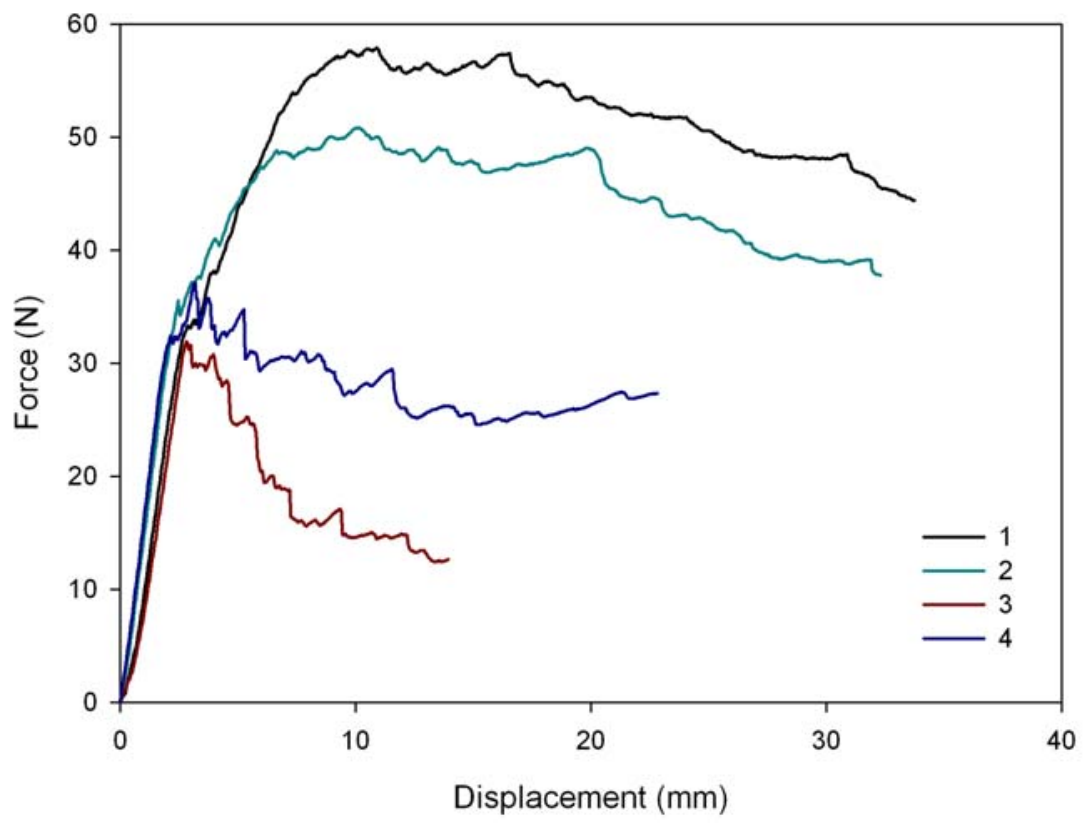

Figure 4. Examples of load-displacement plots. Material B 


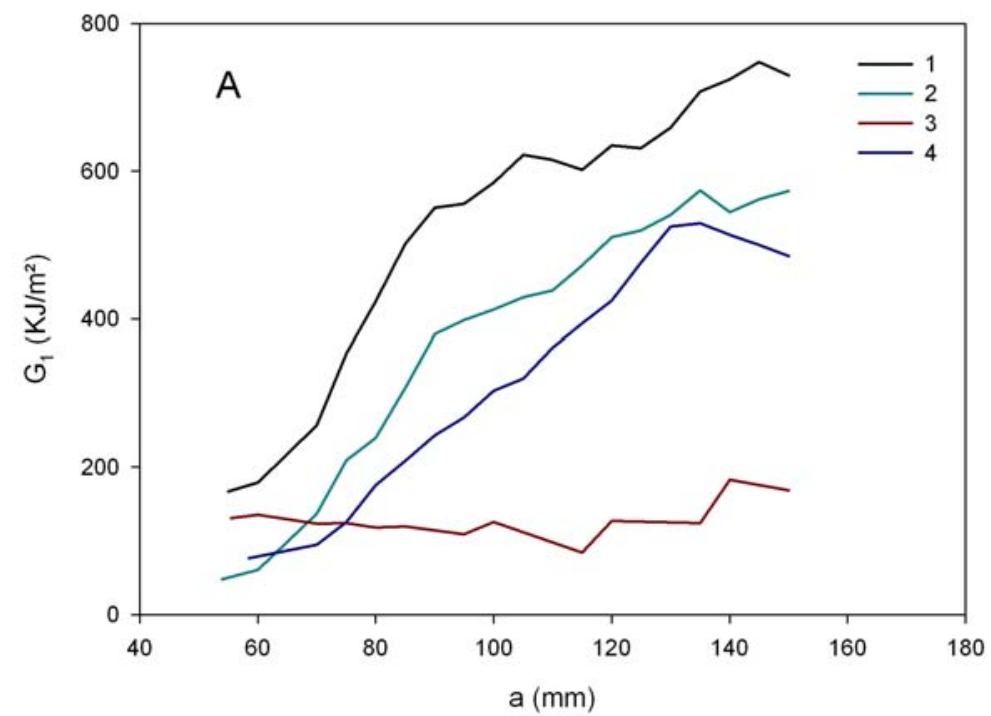

Figure 5 - Composite A - Examples of $\mathrm{R}$ curves for different lamination procedures.

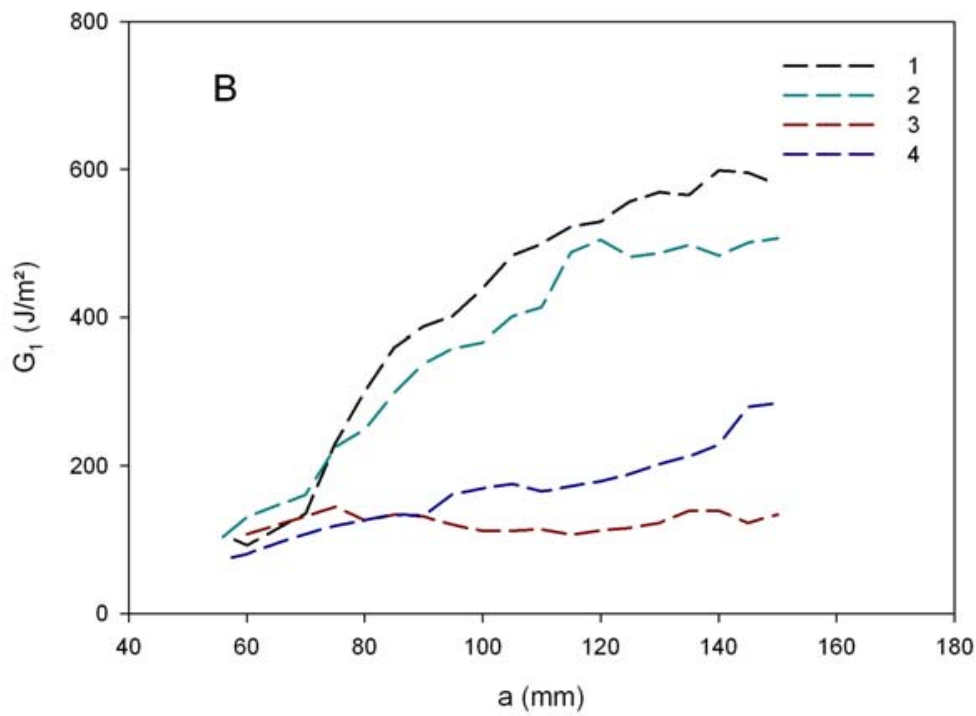

Figure 6 - Composite B - Examples of R curves for different lamination procedures. 

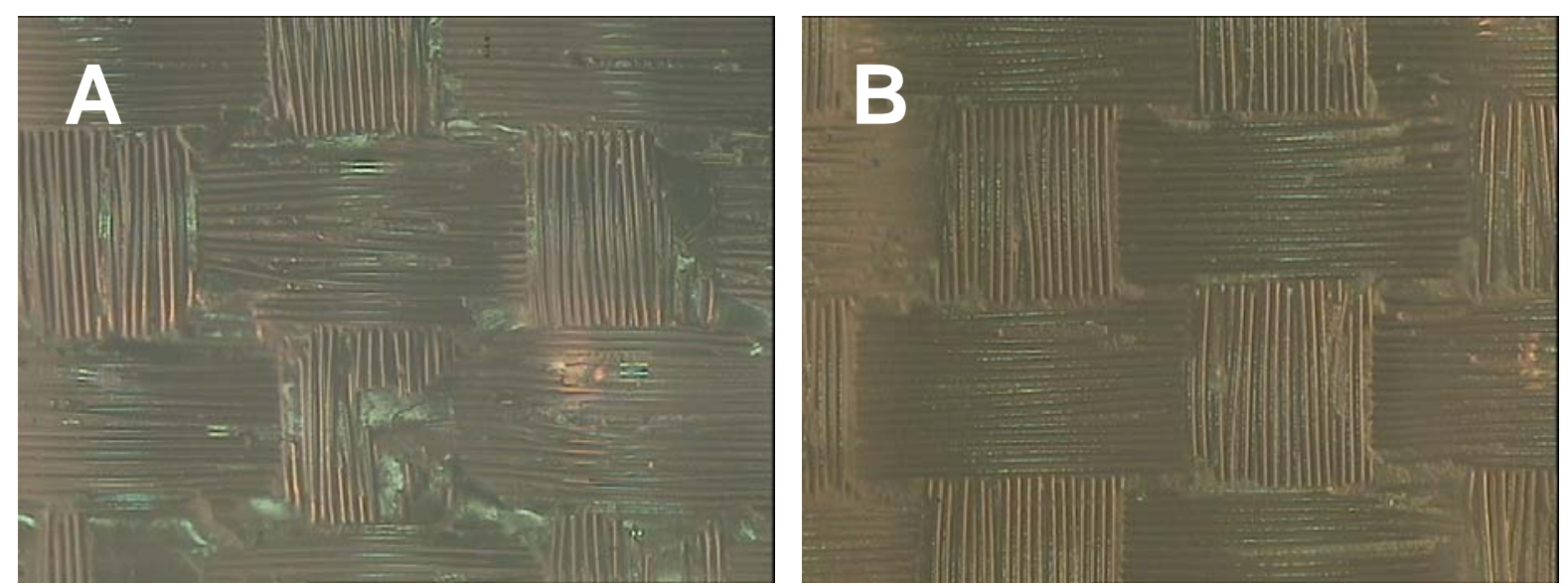

Figure 7. Fracture surfaces of specimens prepared with lamination procedure 3. Crack propagation in vertical direction. 


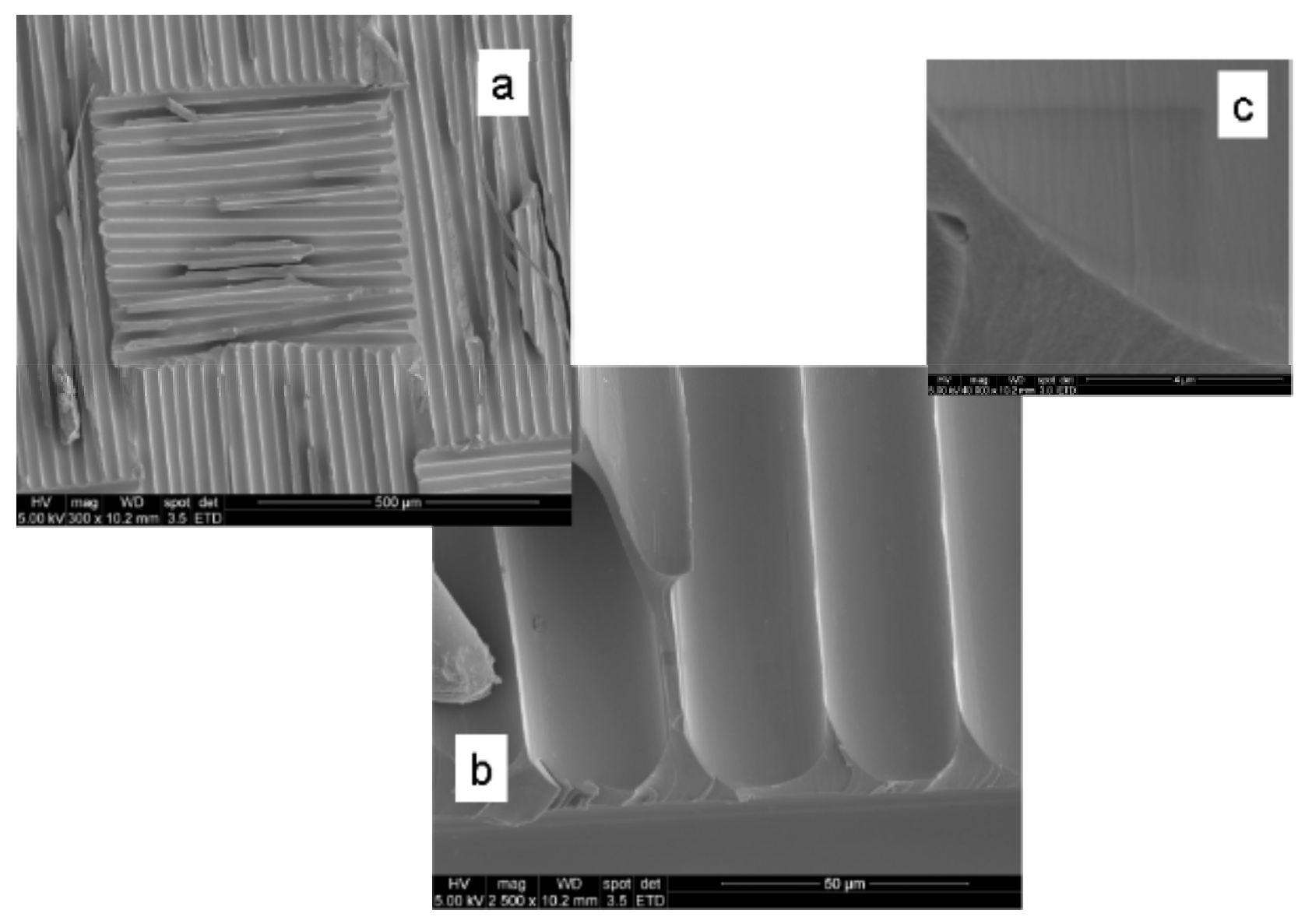

Figure 8. SEM photos of new surface after removal of peel ply. one week after lamination. before overlamination. 


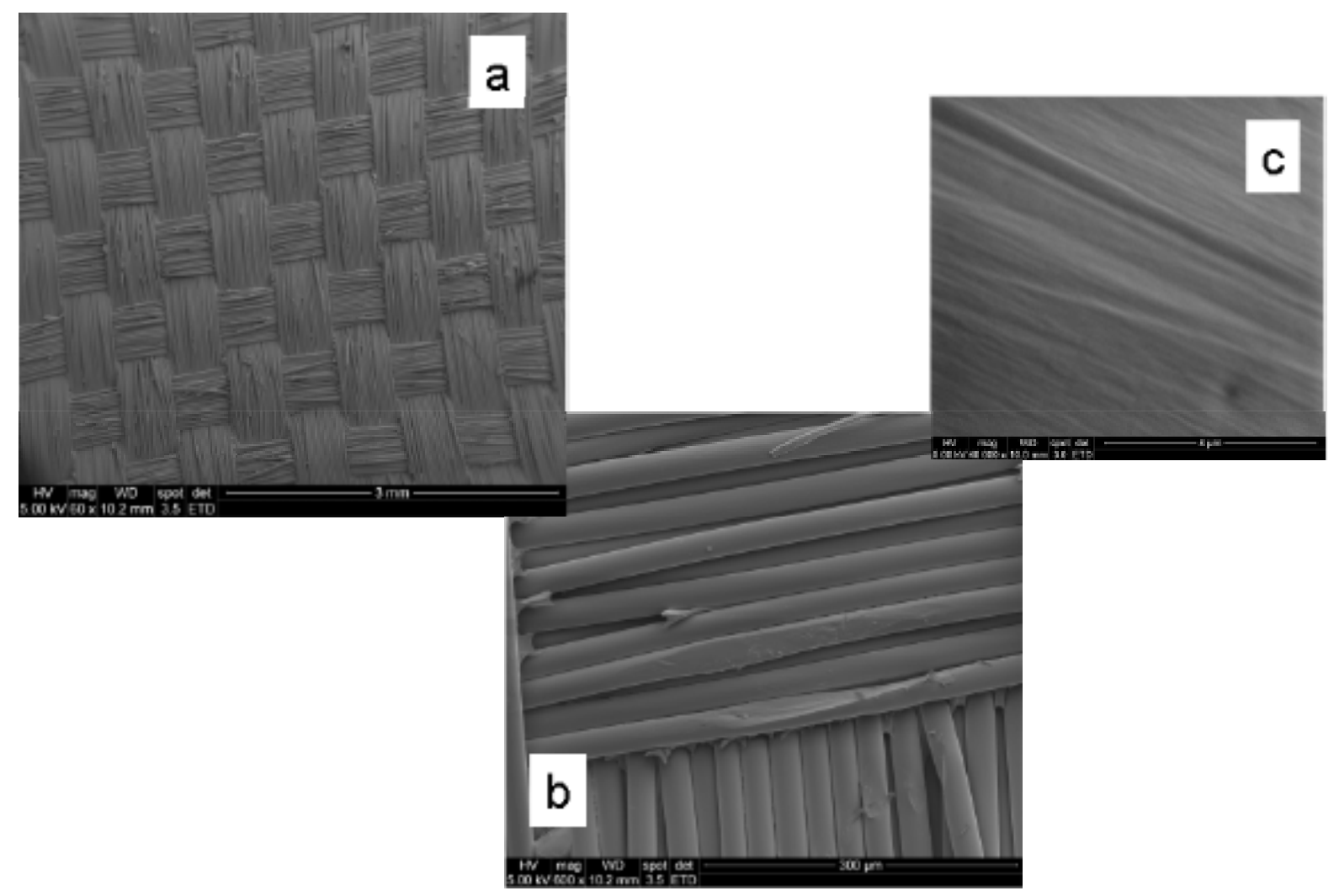

Figure 9. SEM photos of peel ply fabric after removal from the surface shown in Figure 8. 
